\title{
Hematological and biochemical profile of person with macrocytic anemia in a tertiary health care centre of Nepal
}

\author{
Rakesh Pathak ${ }^{1}$, Sujata Pudasaini ${ }^{1}$, Sushmita Ghimire ${ }^{1}$, Anil Singh Basnyat ${ }^{2}$, Anuj \\ $\mathrm{KC}^{3}$
}

${ }^{\prime}$ Department of Pathology, Nepal Medical College Teaching Hospital, Kathmandu, Nepal

${ }^{2}$ National Ayurvedha Research and Training Center, Kirtipur, Kathmandu, Nepal

${ }^{3}$ Department of Medicine, Nepal Medical College Teaching Hospital, Kathmandu, Nepal

\author{
Keywords: \\ Anemia; \\ Folic acid; \\ Macrocytic; \\ Red blood cell indices; \\ Vitamin B12;
}

\begin{abstract}
Background: Anemia is a nutritional problem worldwide with an increased risk of morbidity and mortality in all age groups. Macrocytic anemia often originates from abnormalities that impair the erythroid precursor maturation in the bone marrow. Since the clinical manifestations of different types of anemias are similar, hematological parameters including hemoglobin, Red blood cell indices, and Peripheral Blood Smear examination are useful in the diagnosis of anemia.
\end{abstract}

Materials and Methods: This was a cross-sectional study done in the Department of Pathology at Nepal Medical College Teaching Hospital. A total of 42 patients between 14 to 62 years with low Hb concentration according to the World Health Organization criteria for anemia were selected and a mean cell volume > $100 \mathrm{fL}$ was taken for study. Peripheral blood smear examination, Red blood cell indices, Vitamin B12, and Folic acid level were evaluated.

Results: There were 42 patients with macrocytic anemia enrolled in the study with a mean age of $31.85 \pm 12.49$ years and with female preponderance. Hemoglobin level was slightly low in males compared to females. Red blood cell indices were slightly higher in males. The difference of serum Vit B12 and Folic acid in male and female was found to be significant.

Conclusions: It was concluded that for the diagnosis of a specific type of anemia, hemoglobin, Red blood cell indices, reticulocytes percent, and PBS examination were important parameters. Serum Folic acid and Vitamin B12 level estimation along with other hematological parameters are important for the diagnosis of macrocytic anemia and its correlation.

\section{Correspondence:}

Dr. Rakesh Pathak, MD

Assistant Professor, Department of Pathology

Nepal Medical College Teaching Hospital, Kathmandu, Nepal

ORCID ID: 0000-0003-0780-7416

Email:dr_rakesh@hotmail.com

Received : July $23^{\text {rd }} 2020$; Accepted : September $16^{\text {th }} 2020$

Citation: : Pathak R, Pudasaini S, Ghimire S, Basnyat AS, KC A. Hematological and biochemical profile of person with macrocytic anemia in a tertiary health care centre of Nepal. J Pathol Nep 2020;10: 1722-7. DOI: 10.3126/jpn.v10i2.30225

Copyright: This is an open-access article distributed under the terms of the Creative Commons Attribution 4.0 International License, which permits unrestricted use, distribution, and reproduction in any medium, provided the original author and source are credited.

\section{INTRODUCTION}

Anemia is a nutritional problem worldwide affecting almost two billion people with an increased risk of morbidity and mortality in young children, adolescent girls, and pregnant women. ${ }^{1,2}$ It is broadly defined as a condition associated with a decreased total amount of Red Blood Cells (RBC) or Hemoglobin $(\mathrm{Hb})$ concentration in blood impairing oxygen circulation which in turn has detrimental effects on maternal and birth outcomes, optimal child growth, impaired learning, reduced work productivity and earning during childhood. ${ }^{3,4}$ Socioeconomic status, traditional habits of eating, irregular eating, and physiological conditions like pregnancy are the risk factors of developing anemia in adolescents. ${ }^{5,6}$ 
According to World Health Organization (WHO), the $\mathrm{Hb}$ concentration less than $13 \mathrm{gm} / \mathrm{dl}$ in men, $12 \mathrm{gm} / \mathrm{dl}$ in nonpregnant women, $11 \mathrm{gm} / \mathrm{dl}$ in pregnant women, $12 \mathrm{gm} /$ $\mathrm{dl}$ in children aged 12 to 14 years, $11.5 \mathrm{gm} / \mathrm{dl}$ in children aged 5-11 years and $11 \mathrm{gm} / \mathrm{dl}$ in children (less than 5 years) are the diagnostic criteria of anemia.7 One of the basis of anemia classification is based on underlying mechanisms like impaired production, increased destruction, and huge blood loss. The second approach classifies anemia according to the change in red cell morphology and often correlates with the cause of red cell deficiency which can be morphologically divided into normocytic, microcytic, or macrocytic. $^{8}$

Depending upon the size, RBCs are called enlarged erythrocytes when Mean Cell Volume (MCV) is $>100 \mathrm{fl}$ which is the characteristic feature of macrocytic anemia which often originates from abnormalities that impair the erythroid precursor maturation in the bone marrow. ${ }^{4,9}$ Megaloblastic anemia is the most common cause of macrocytic anemia due to the low availability of vitamin B12 and folic acid for coenzymes required for thymidylate and purine synthesis which results in impaired DNA synthesis, ineffective erythropoiesis, and intramedullary hemolysis. ${ }^{10,11}$

Since the clinical manifestations of different types of anemias are similar, the differential diagnosis of macrocytic anemia can be done with the physical examination, hematological parameters including $\mathrm{Hb}, \mathrm{RBC}$ indices like MCV, Mean Corpuscular Hemoglobin (MCH), Mean Corpuscular Hemoglobin Concentration (MCHC) along with Peripheral Blood Smear (PBS) examination. The main objective of this study was to assess the hematological and biochemical parameters in a person with macrocytic anemia..

\section{MATERIALS AND METHODS}

This cross-sectional study was done in the Department of Pathology at Nepal Medical College Teaching Hospital from November 2019 to April 2020. Ethical approval was taken from the Institutional Review Committee, Nepal Medical College and Teaching hospital, and informed consent from the patients was taken before sample handling. A total of 42 patients between 14 to 62 years with low $\mathrm{Hb}$ concentration $(\mathrm{gm} / \mathrm{dl})$ for anemia diagnosis according to WHO criteria and MCV level $>100 \mathrm{fl}$ were selected. The blood samples were collected in vials containing Ethylene Diamine Tetra Acetic acid (EDTA) anticoagulant agent and were immediately analyzed in Sysmex 5 parts XS-500i automated hematology analyzer in the Clinical Pathology laboratory. The evaluated parameters included $\mathrm{Hb}, \mathrm{MCV}, \mathrm{MCH}, \mathrm{MCHC}$, reticulocytes count, and PBS.

Hemoglobin concentration and $\mathrm{RBC}$ indices range for the diagnosis of anemia according to $\mathrm{WHO}^{7}$
The reference interval for RBC indices were:

Mean Cell Volume (MCV): 80-100 fL

Mean Cell Hemoglobin (MCH): 27-32 pg

Mean Cell Hemoglobin Concentration (MCHC): 32-36 $\mathrm{gm} / \mathrm{dl}$

Reticulocytes: $($ In adults $=0.5 \%-2.5 \%$ and In infants $=$ $0.5 \%-7 \%$ )

When MCV was greater than $100 \mathrm{fl}$, the anemia was reported as Macrocytic anemia and undertaken for the study.

\section{Peripheral Blood Examination}

For the PBS examination, smears were made using EDTA blood and allowed to air dry. Then, $0.25 \%$ of the Wright stain was poured on the entire slide and left for 2-3 minutes. An equal volume of distilled water was added. After 15 minutes slides were thoroughly washed, dried, and examined under a light microscope. PBS findings like macrocytic or normocytic cells, hypersegmented neutrophils, polychromatic cells, basophilic stippling, teardrop cells, etc were noted.

\section{Reticulocyte Count}

Equal volumes of the patient's EDTA blood and new methylene blue reagent were mixed in a test tube and allowed to incubate at $37^{\circ} \mathrm{C}$ for 10 minutes. Then the smears were made and examined under oil immersion.

\section{Biochemical analysis}

For serum Vitamin B12 and Folic acid analysis, venous blood samples were collected in gel vials, centrifuged at 3500 RPM for 10 minutes, and then estimation was done in Fully automated VITROS ECi Q, Johnson \& Johnson, USA Machine.

Reference interval for Vitamin B12 $=211-911 \mathrm{pg} / \mathrm{ml}$ Reference interval for Folic acid $=3.56-20.0 \mathrm{ng} / \mathrm{ml}$

\section{Data analysis}

Age, gender, $\mathrm{Hb}$ concentration, $\mathrm{MCV}, \mathrm{MCH}, \mathrm{MCHC}$,

Table 1: Normal hemoglobin concentration at different age and sex of the individuals ${ }^{7}$

\begin{tabular}{lc}
\hline Category & $\begin{array}{c}\text { Hemoglobin concenrtation } \\
(\text { gm/dl) }\end{array}$ \\
\hline Children 6-59 months & $<11$ \\
Children 5-11 years & $<11.5$ \\
Children 12-14 years & $<12$ \\
Non-pregnant women (15 years) & $<12$ \\
\hline Pregnant women & $<11$ \\
Men (15 years) & $<13$
\end{tabular}




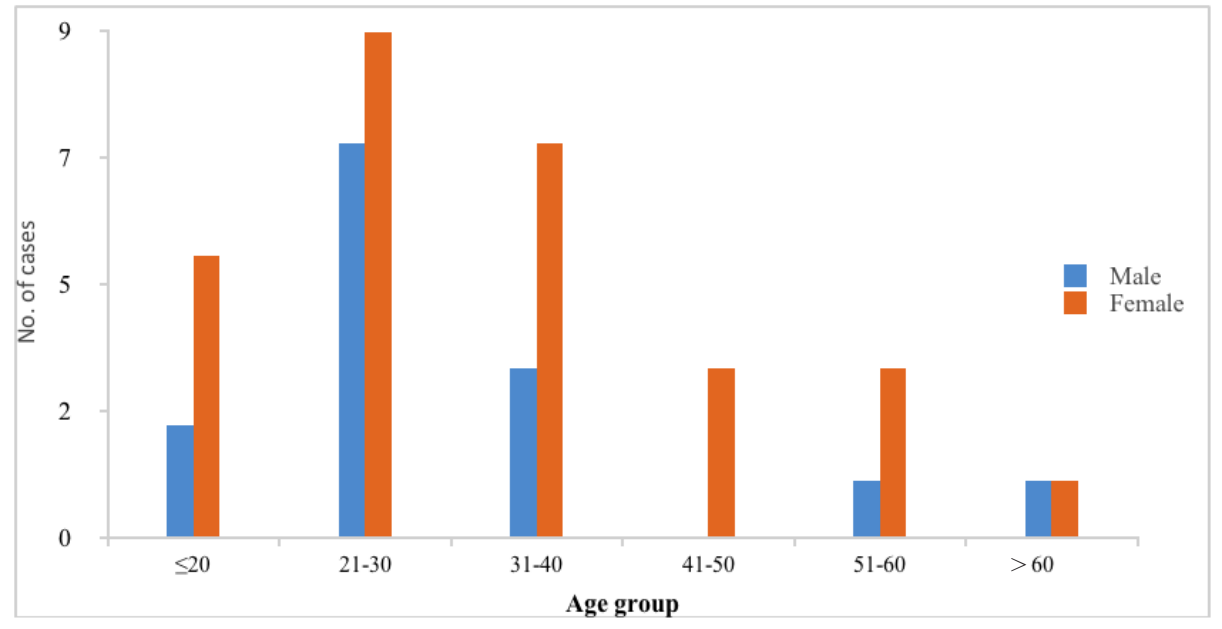

Figure 1: Age and Gender wise distribution of Macrocytic anemia patients

reticulocyte percentage, and other parameters were determined. Serum Vit B12 and folic acid were also analyzed. The data obtained were managed in MS Excel 2016 and later analyzed using IBM SPSS version 20.

\section{RESULTS}

Our study comprised a total of 42 patients with macrocytic anemia and the age ranged from 14 to 62 years with a mean age of $31.85 \pm 12.49$ years. There were 14 males $(33.33 \%)$ and 28 females $(66.67 \%)$ with a male: female ratio of $1: 2$.

Figure 1 demonstrates the age-wise distribution of male and female macrocytic anemia patients with a higher incidence of 16 cases ( 7 males, 9 females) in the age group 21-30 years and the least 2 cases ( 1 male, 1 female) in $>60$ years of age group.

Age-wise distribution of $\mathrm{Hb}$ and $\mathrm{RBC}$ indices was compared and $\mathrm{Hb}$ level was found to be more than $8 \mathrm{gm} \%$ in the age group 41- 50 years, which was more compared to other patients. The lowest Hb level $(7.16 \pm 1.56 \mathrm{gm} / \mathrm{dl})$ was seen in the age group 21-30 years. The highest MCV was found in a patient less than 20 years $(109.14 \pm 5.81 \mathrm{fl})$ and smallest in patients above 60 years $(103 \pm 2.82 \mathrm{fl})$. Similarly, the $\mathrm{MCH}$ and $\mathrm{MCHC}$ levels were found higher in 41-50 years (34.72 $\pm 1.45 \mathrm{pg}$ and $35.5 \pm 2.145 \%$ ) whereas lower in 51-60 years (30.2 $\pm 3.38 \mathrm{pg}$ and $31.66 \pm 2.66 \%$ ) (Table 2 and 3 ).

In PBS examination, out of 42 cases, 34 cases $(80.9 \%)$ were identified as macrocytic anemia while 8 cases $(19.1 \%)$ were identified as normocytic anemia. These macrocytic

Table 2: Gender wise distribution of hematological parameters and reticulocytes

\begin{tabular}{lcccc}
\hline Variables & $\begin{array}{c}\text { Total } \\
\text { Mean } \pm \text { SD }\end{array}$ & Male (n=14) & Female (n=28) & $\begin{array}{c}\text { p-value } \\
(<\mathbf{0 . 0 5})\end{array}$ \\
\hline Age (years) & $31.85 \pm 12.49$ & $31 \pm 11.97$ & $32.28 \pm 12.94$ & 0.375 \\
Hemoglobin (gm/dl) & $7.38 \pm 1.44$ & $7.15 \pm 1.64$ & $7.5 \pm 1.34$ & 0.249 \\
MCV (fl) & $107.38 \pm 6.21$ & $108.35 \pm 6.27$ & $106.89 \pm 6.24$ & 0.240 \\
MCH (pg) & $33.57 \pm 3.90$ & $34.70 \pm 3.27$ & $33.01 \pm 4.12$ & 0.078 \\
MCHC (\%) & $34.13 \pm 3.11$ & $34.35 \pm 2.74$ & $34.02 \pm 3.32$ & 0.366 \\
Reticulocytes (\%) & $4.09 \pm 2.52$ & $4.92 \pm 3.47$ & $3.68 \pm 1.83$ & 0.11
\end{tabular}

${ }^{*} p$-value compares the Mean $\pm S D$ values of males and females by independent samples $t$-test.

Table 3: Age wise distribution of hematological parameters(Mean \pm SD)

\begin{tabular}{|c|c|c|c|c|c|}
\hline Age (years) & Hemoglobin (gm/dl) & $\operatorname{MCV}(f)$ & MCH (pg) & MCHC (\%) & Reticulocytes (\%) \\
\hline$\leq 20$ & $7.51 \pm 1.19$ & $109.14 \pm 5.81$ & $32.58 \pm 3.95$ & $33.61 \pm 3.06$ & $3.25 \pm 0.81$ \\
\hline $21-30$ & $7.16 \pm 1.56$ & $108 \pm 6.97$ & $34.35 \pm 4.56$ & $34.49 \pm 2.86$ & $4.55 \pm 3.37$ \\
\hline $31-40$ & $7.26 \pm 1.71$ & $107.2 \pm 7.03$ & $33.48 \pm 3.82$ & $34.11 \pm 4.22$ & $4.53 \pm 2.39$ \\
\hline $41-50$ & $8.3 \pm 1.35$ & $105.25 \pm 5.31$ & $34.72 \pm 1.45$ & $35.5 \pm 2.14$ & $3.7 \pm 0.66$ \\
\hline $51-60$ & $7.4 \pm 0.60$ & $106 \pm 3.46$ & $30.2 \pm 3.38$ & $31.66 \pm 2.66$ & $4.1 \pm 2.28$ \\
\hline$>60$ & $7.25 \pm 1.48$ & $103 \pm 2.82$ & $34.15 \pm 0.35$ & $34.2 \pm 0.42$ & $2.05 \pm 2.33$ \\
\hline
\end{tabular}


Table 4: Gender wise distribution of Vitamin B12 and Folic acid

\begin{tabular}{lcccc}
\hline Parameters & Total & Male $(\mathbf{n}=\mathbf{5})$ & Female $(\mathbf{n}=\mathbf{1 5})$ & p - value \\
\hline Vitamin B12 $(\mathbf{p g} / \mathbf{m l})$ & $202.7 \pm 42.85$ & $180.5 \pm 8.31$ & $212.21 \pm 48.29$ & 0.01 \\
Folic acid $(\mathbf{n g} / \mathbf{m l})$ & $3.43 \pm 1.86$ & $2.67 \pm 0.64$ & $3.75 \pm 2.13$ & 0.05
\end{tabular}

and normocytic anemia were demonstrated with additional characteristics like hypersegmented neutrophils in 19 cases, polychromatic cells in 25 cases, basophilic stippling in 4 cases, and teardrop cells in 2 cases.

Among 42 patients, only 20 had serum Vitamin B12 and Folic acid reports available out of which 15 cases had decreased levels of both biochemical markers while 5 cases had the normal level. The overall serum levels of Vitamin B12 and folic acid levels were found to be decreased in macrocytic anemia patients. Also, serum concentrations of these markers were found significantly different among male and female anemia patients $(\mathrm{p}<0.05)$ (Table 4).

\section{DISCUSSION}

Primarily Vitamin B12 and folic acid deficiencies are the most probable etiology of macrocytosis $(\mathrm{MCV}>100 \mathrm{fl})$ leading to macrocytic anemia but in some cases, etiology remains unclear. However, anemia with normal MCV may indicate a chronic or mixed type of anemia. In this study, we used hematological and PBS examination to identify the macrocytic anemia and correlated the findings with their gender and age groups.

In our study, the maximum incidence of macrocytic anemia was seen in females (66.67\%) than in males $(33.33 \%)$ with the peak age group 21-30 years (mean 32.28 \pm 12.94 ). In contrast, Banjare B et al, Deepankaret al, and Iqbal S et al observed the highest incidence of macrocytic anemia in males than females. ${ }^{2,13,14}$ A study by Rayamajhi et al reported $48 \%$ of pregnant women were anemic with the maximum incidence in the age group 15-30 years. ${ }^{5}$ Similar age distributions were also observed by Unnikrishanan et al and Deepankar et al, with mean age 35.7 \pm 16.1 and $39.06 \pm$ 8.9 years respectively. ${ }^{12,13}$

In the age-wise distribution of $\mathrm{Hb}$, the patients of age group 21-30 years were present with the lowest $\mathrm{Hb}$ level $7.16 \pm 1.56 \mathrm{gm} / \mathrm{dl}$ whereas $41-50$ years age group patients had the highest $\mathrm{Hb}$ level $8.3 \pm 1.35 \mathrm{gm} / \mathrm{dl}$. In all cases, the MCV was found to be increased. The largest RBC size (MCV) was found in patients below 20 years $(109 \pm 5.81 \mathrm{fl})$ and the smallest in above 60 years $(103 \pm 2.82 \mathrm{fl})$. Regarding $\mathrm{MCH}$, in most cases $(69 \%)$ the value was found to be elevated with a higher incidence in the age group 41-50 years $(34.72 \pm 1.45 \mathrm{pg})$ and lower in 51-60 years $(30.2 \pm 3.38 \mathrm{pg})$. Similarly, MCHC values were found to be higher in patients of age group $41-50$ years $(35.5 \pm 2.145 \%)$ whereas lower in 51-60 years $(31.66 \pm 2.66 \%)$. Similarly, we found the maximum reticulocytes in the age group 21-30 years
$(4.55 \pm 3.37 \%)$ whereas the minimum level in people above 60 years $(2.05 \pm 2.33 \%)$.

In contrast to our study, Pudasaini $\mathrm{S}$ et al observed those with low $\mathrm{MCH}$ had low $\mathrm{MCHC}$ levels, and low $\mathrm{MCH}$ and $\mathrm{MCHC}$ values were observed in children of the age group 12-14 years. ${ }^{15} \mathrm{~A}$ study by Barve $\mathrm{S}$ et $\mathrm{al}^{16}$ reported in megaloblastic anemia, low RBC count was due to premature RBC's destruction and anemic patients had low PCV but high $\mathrm{MCV}, \mathrm{MCH}$, and $\mathrm{MCHC}$ values which correlates well with this study.

Kannan A et al reported that out of 100 cases of macrocytosis, $62 \%$ had non-megaloblastic macrocytosis whereas $38 \%$ had megaloblastic anemia and bone marrow disorders (46\%) is the most common cause of macrocytosis including acute and chronic leukemia, aplastic anemia, multiple myeloma, and myelofibrosis. A significant difference in MCV was observed between megaloblastic and non-megaloblastic macrocytosis. ${ }^{17}$

In this study, out of 20 available reports we observed 15 cases $(75 \%)$ had decreased level of both Vitamin B12 and folic acid whereas 5 cases $(25 \%)$ had a normal level of those markers comprising overall decreased serum level of both Vitamin B12 and Folic acid $(202.7 \pm 42.85 \mathrm{pg} / \mathrm{ml}$ and $3.43 \pm 1.86 \mathrm{ng} / \mathrm{ml}$ respectively) and the difference between males and females were found to be statistically significant $(\mathrm{p}<0.05)$. In contrast to our findings, Iqbal SP et al found out of 220 megaloblastic anemia patients, $71 \%$ of folic acid deficient patients had Vitamin B12 deficiency as well but there was no any significant difference between male and female patients. ${ }^{14}$

Similarly, Agrawal L et al observed that out of 100 macrocytic anemia patients, $55 \%$ of patients were diagnosed with Vitamin B12 deficiency and 8\% with folate deficiency. ${ }^{19}$ Deepankar et al found $54 \%, 25 \%$, and $21 \%$ of participants with Vitamin B12 deficiency, folic acid deficiency, and both Vitamin B12 and folic acid deficiency respectively. ${ }^{13} \mathrm{~A}$ study by Wyckoff KF et al reported subjects with decreased serum vitamin B12 is likely to be without macrocytosis during the period of post fortification and folic acid fortification led to macrocytosis correction related to vitamin B12 insufficiency. ${ }^{18}$ A review study by Batool S et al reported vitamin B12 and folic acid deficiency is the factor responsible for impaired DNA synthesis, ineffective erythropoiesis, and intramedullary hemolysis which ultimately breaks red blood cells. ${ }^{11}$

Out of 42 cases of PBS examinations, we found 34 cases 
$(80.9 \%)$ were identified as macrocytic anemia while 8 cases $(19.1 \%)$ were normocytic anemia. These macrocytic and normocytic anemia were had characteristic features like hypersegmented neutrophils (19 cases), polychromatic cells ( 25 cases), basophil stippling (4 cases), and teardrop cells ( 2 cases). Similarly, Deepankar et al found that out of 97 PBS studies of megaloblastic anemic patients, the presence of macrocytes was common in $88 \%$ of patients and hypersegmented neutrophils were observed in $43 \%$ cases. ${ }^{13}$ A study done by Agrawal et al reported macro-ovalocytes, teardrop cells, basophilic stippling, polychromasia, hypersegmented neutrophils or pancytopenia on PBS examinations. ${ }^{19}$

Aslinia $\mathrm{F}$ et al described macrocytic anemia as an anemic state characterized by the presence of abnormal large RBCs which is usually recognized by automated cell counter and PBS review. A careful review of PBS noting RBC morphology, cellular elements, and the specific features on the smear provide important information about the possible etiology of the anemia. ${ }^{20}$

In this study, we found the overall reticulocyte value of macrocytic anemia patients as $4.55 \pm 3.37 \%$ accounting for $4.92 \pm 3.47 \%$ in males and $3.68 \pm 1.83 \%$ in females, with maximum value in the age group 21-30 years $(4.09 \pm 2.5 \%)$ while minimum in the age group above 60 years. Out of 42 cases, we observed 35 cases (83\%) with increased reticulocytes while 7 cases $(13 \%)$ had a normal level. In contrast to our study, Rairikar SS et al reported among severe anemia cases, $62.5 \%$ of cases had normal reticulocytes whereas $9.4 \%$ cases had low and $28.12 \%$ cases had increased count. ${ }^{21}$

Likewise, D'Onofrio et al observed patients with microcytic anemia due to iron deficiency (58 patients) and heterozygous B-thalassemia (40 patients), and macrocytosis (28 patients) all had larger reticulocytes than mature RBCs by $24 \%$ to $35 \% .{ }^{22}$ A study by Balci YI et al claimed that reticulocytes could be the useful marker for differentiating iron deficiency anemia and vitamin B12 deficiency anemia. ${ }^{23}$

In this study, the gender-wise distribution of $\mathrm{Hb}, \mathrm{RBC}$ indices, PBS, and reticulocytes showed no significant differences between male and female patients. In contrast, serum Vitamin B12 and folic acid levels were found to be statistically different $(\mathrm{p}<0.05)$ in male and female anemic patients. A study by Sukla et al shows a similar finding which is comparable with our study. ${ }^{24}$

\section{CONCLUSIONS}

In this study, we found the maximum incidence of macrocytic anemia in females of young age group. RBC indices like $\mathrm{MCV}, \mathrm{MCH}, \mathrm{Hb}$, reticulocytes percent and PBS are the important factors for the diagnosis of anemia. Serum Vitamin B12 and Folic acid test further aid in the diagnosis of megaloblastic anemia. Thus the clinical, hematological, and biochemical parameters are the important tools for diagnosing macrocytic anemia and further help in differentiating megaloblastic anemia from non-megaloblastic anemia.

\section{Recommendations}

This study recommends a biochemical profile in cases of macrocytic anemia for definite diagnosis and clinical management.

\section{Conflict of Interest: None}

\section{REFERENCES}

1. Kassebaum NJ, Jasrasaria R, Naghavi M, et al. A systematic analysis of global anemia burden from 1990 to 2010. Blood 2014;123:61524. Crossref

2. Banjara B, Das A, Gahine R, et al. Evaluation of anemia in children using minimum haematological parameters and correlation of red cell distribution width with mean corpuscular volume for prediction of early stages of nutritional anemia. J Med SciCli Res 2019;7:34350. Crossref

3. International Food Policy Research Institute. Global Nutrition Report 2016: From promise to impact: Ending malnutrition by 2030. Washington DC. $\underline{\text { Crossref }}$

4. Khan N, Mallik MK, Mallik A. Evaluation of the Hematological Parameters in Correlation with Peripheral Smear Examination to Analyze the Prevalence, Type and Severity of Anemia in Different Age and Sex in Shahjahanpur, Uttar Pradesh. Int J Health Sci Res 2017;7:16-21.

5. Rayamajhi N, Mishra SK, Gautam N, et al. Prevalence of anemia in pregnant women attending a tertiary level hospital in western region, Nepal. J UniColl Med Sci 2016;4:17-9. Crossref

6. Balci YI, Karabulut A, Gurses D, et al. Prevalence and risk factors of anemia among adolescents in Denizli, Turkey. Iran J Pediatr 2012;22:77-81. Crossref

7. World Health Organization. Haemoglobin concentrations for the diagnosis of anaemia and assessment of severity. Vitamin and mineral nutrition information system. Geneva, WHO, 2011 (WHO/ NMH/NHD/MNM/11.1) ( Cited on 5th July 2020) Website

8. Kumar V, Abbas AK, Fausto Nelson. Red blood cell and bleeding disorders. In: Robbins and Cotran Pathologic basis of disease. 7th ed. Elsevier: Noida, India; 2005. pp 619-59.

9. Mckenzie SB, Williams JL. Megaloblastic and nonmegaloblastic anemias. In: Clinical laboratory hematology. 2nd ed. Kendalville: Julie Levin Alexander; 2010:257-78.

10. Ahmed T, Rahman AS, Ahmed S, et al. Frequency of Vitamin B12 and Red Cell Folate Deficiency in Macrocytic Anaemia. J Basic Appl Sci 2012;8:706-13. Crossref

11. Batool S, Iqbal R. Macrocytic anemia: A review. J Entomol Zoo Studies 2016;4:544-7. $\underline{\text { Crossref }}$

12. Unnikrishnan V, Dutta TK, Badhe BA, et al. Clinico-aetiologic profile of macrocytic anemias with special reference to megaloblastic anemia. Indian J Hematol Blood Transfus 2008;24:155-65. Crossref

13. Deepankar P, Roshan R, Gupta HK, et al. Relative prevalence of vitamin B12 and folic acid in megaloblastic anemia and its clinical etiological profile in a tertiary care center. Int J Sci Study 2018;6:2330. Crossref 
14. Iqbal SP, Kakepoto GN, Iqbal SP. Vitamin B12 deficiency- a major cause of megaloblastic anaemia in patients attending a tertiary care hospital. J Ayub Med Coll Abbottab 2009;21:92-4. $\underline{\text { Website }}$

15. Pudasaini S, Pant PP, Kafle N, et al. Study of red cell indices and reticulocyte count in person with anemia at a tertiary care hospital of Kathmandu. Nepal Med Coll J 2019;21:1-6. $\underline{\text { Crossref }}$

16. Bavre S, Patel D, Shiromani KK, et al. Role of RBC count and $\mathrm{RBC}$ indices in diagnosing and differentiating anemias caused due to various clinical situations in a tertiary care hospital in Vadodara, Gujarat. J Evid Based Med Hlthc 2015;2:8146-8. $\underline{\text { Crossref }}$

17. Kannan A, Tilak V, Rai M, et al. Evaluation of clinical, biochemical and hematological parameters in macrocytic anemia. Int J Res Med Sci 2016;4:2670-8. Crossref

18. Wyckoff KF, Ganji V. Proportion of individuals with low serum vitamin B-12 concentrations without macrocytosis is higher in the post-folic acid fortification period than in the pre-folic acid fortification period. Am J Clin Nutr 2007;86:1187-92. Crossref
19. Agrawal L, Ramawat J, Agrawal M, et al. A study on prevalence and causative factors of megaloblastic anaemia in Hadoti region. Ann Appl Bio-Sci 2017;4:31-4. Crossref

20. Aslinia F, Mazza JJ, Yale SH. Megaloblastic anemia and other causes of macrocytosis. Clin Med Res 2006;4:236-41. Crossref

21. Rairikar SS, Ahire AP, Baheti NR, et al. A study of Blood Cell Indices and Reticulocyte Count in cases of Anaemia in Females in Reproductive Age Group. MVP J Med Sci 2014;1:56-60. Crossref

22. D'Onofrio G, Chirillo R, Zini G, et al. Simultaneous measurement of Reticulocyte and RedBlood Cell Indices in healthy subjects and patients with Microcytic and Macrocytic Anemia. Blood 1995;85:818-23. Crossref

23. Balci YI, Ozgurler A, Polat A, et al. Evaluation of reticulocyte parameters in iron deficiency, vitamin B12 deficiency and mixed anemia. Clin Lab 2016;62:343-7. $\underline{\text { Crossref }}$

24. Kishore SK, Nagar R, Raman R. Vitamin B12 and folate deficiency major contributing for anaemia. Short Report 2014;9:E45-E48. $\underline{\text { Crossref }}$ 